\title{
Dispatch
}

\section{Teachers for Teachers: Advocating for Stronger Programs and Policies for and with Refugee Teachers in Kakuma Refugee Camp, Kenya}

\author{
MARY MENDENHALL \\ Teachers College, Columbia University, USA
}

Teachers are expected to facilitate learning for children and youth, attend to their students' diverse academic needs, and provide emotional support and encouragement, while simultaneously meeting the expectations and demands of students, families, colleagues, school leaders and the larger education system. In crisis-affected and displacement contexts, teachers are regularly expected to perform these duties with little to no training, support or materials (Burns \& Lawrie, 2015). Jackie Kirk, along with her colleague, Rebecca Winthrop, captured the inherent tension of this situation and the uncertain sense of identity that teachers in these contexts experience. Kirk and Winthrop (2007, p. 719) proposed the ideas of "spontaneous teachers," who become teachers reluctantly given the circumstances, and "tentative teachers," who feel uncertain about serving as teachers or remaining in the profession. Their conceptualization of teacher identity rings true for the teachers that my graduate students and I have been working within Kakuma refugee camp in northwestern Kenya since 2013. A similar sentiment is captured in the following quote from a young refugee teacher in the camp from South Sudan:

Yes, I'm happy to be a teacher, but with a condition. If I can get training and prove that I'm a teacher, that's when I will tell that I'm happy to be a teacher. But as per now, I have not yet known the sweetness of being a teacher because I have not been trained.... As per now, I don't call myself a good teacher. I am not good because I am not a professional. (Male teacher, South Sudan, July 2015) 
Inspired by Kirk and Winthrop's work on teacher identity in crisis contexts, and with hopes of raising the profile of these teachers, my students and I have been engaged in an intertwined research-practice approach that aims to better support teacher professional development in refugee settings, while simultaneously creating opportunities for teachers in the camp to comment, critique, shape and continually refine our collaborative approach to supporting their needs. As we continue to advocate for the right to education for all children around the world, including the 75 million out of school due to conflict and crisis (Nicolai et al., 2016), we must simultaneously take more concerted action in the name of social justice to support the teachers working in these contexts. This dispatch will share and reflect on our efforts to collaborate with teachers in Kakuma over the years and how we continue to do so through the more recent creation of our "Teachers for Teachers" initiative.

\section{Connecting with Teachers in Kakuma Refugee Camp}

Kakuma refugee camp is situated near the South Sudan border and has existed since 1992. The camp currently hosts 177,798 refugees from 20 different countries (UNHCR, 2017). The majority of the refugees hail from Somalia and South Sudan, but also Sudan, the Democratic Republic of Congo, Ethiopia, Burundi and Uganda (UNHCR, 2017). Currently, 86\% of all teachers in the camp are refugees (UNHCR, 2017), and as new recruits to the teaching profession, they are relatively unprepared to manage enormous class sizes (average: one teacher to 96 pupils), provide psychosocial support to learners, handle multiple languages spoken in the classroom and cope with a scarcity of resources including desks and learning materials.

I first visited Kakuma refugee camp in 2013 as part of a research team examining the quality of education for refugees in both camp and urban schools in Kenya. I was shocked that so few teachers had received training. Even though this camp had existed for over two decades, only $20 \%$ had received any training (see Mendenhall et al., 2015). The Kenyan government had recently recognized the schools in the camp as national schools, as they had been teaching the Kenyan curriculum for some time. The protracted nature of the crises in neighboring countries that caused refugees to come to Kakuma, however, situated the camp in the gray zone between humanitarian relief and development aid, which may provide a partial explanation for the limited teacher support provided given overall decreases in funding levels for camp activities. ${ }^{1}$

In the summer of 2015, I was able to return to Kakuma with two graduate

\footnotetext{
${ }^{1}$ It is important to note that in recent years there have been considerable developments around teacher training offered by NGOs working in the camp and in partnership with Kenyan tertiary institutes or foreign universities.
} 
students, to conduct a research study on refugee teacher identity and to pilot a teacher training program as part of a larger inter-agency effort to bolster support to teachers working in refugee contexts. ${ }^{2}$ During our time in Kakuma, we conducted multi-part interviews over several weeks with teachers about their experiences as learners (many of them grew up and attended schools in Kakuma), their experiences as teachers, and their ideas about their own professional development needs. In between these interviews, we were also piloting the training program on the weekends. We quickly realized how valuable this approach was for creating feedback loops, as information shared during the interviews informed our conversations in the training room and vice versa. The combination of one-to-one interviews and group training observations also often illuminated interesting contradictions or provided more nuance to the discussion that we may not have uncovered through a more singular approach that emphasized research or training alone. For example, in the first interview about teachers' own childhood experiences as students, all 27 of the teachers commented on the negative impressions left by their childhood teachers' use of corporal punishment, while in the second interview, teachers would often justify why they now used corporal punishment. In the training room, more complexities would emerge in conversation with other teachers about the positive and negative implications of using harsher physical punishments while also providing a space to consider alternative and more positive practices of classroom discipline. This approach proved to be an important opportunity to triangulate teachers' perceptions through different methodologies and across different settings in which we interacted with the same teachers.

Another important decision during this early phase was to co-facilitate the pilot trainings with local partners. Our entire approach greatly benefited from the involvement of a head teacher, who was also a refugee in the camp. This teacher worked with our team on a weekly basis to review the draft training materials and to help make adjustments to the language and vignettes embedded in the curriculum to ensure that they were culturally responsive to the needs of the teachers (Emdin, 2016; Ladson-Billings, 1995). He then cofacilitated or led select sessions during each training workshop, a practice that we continue to emulate in our current activities in the camp. Our approach embraces Kirk and Winthrop's (2007, p. 720) notion of "alternatively qualified teachers," which aims to acknowledge the "very valuable qualities and abilities that inexperienced and unqualified teachers do have." Teachers' involvement in developing and facilitating the training sessions was one way to show our respect for these teachers and the expertise that they bring with them to these environments.

\footnotetext{
${ }^{2}$ For more information and access to the open-source training materials that the Teachers in Crisis Contexts Working Group has produced, please visit: http://www.ineesite.org/en/ticccollaborative
} 


\section{Expanding Support for Teachers in Refugee and Crisis Contexts}

Building on this strong foundation, we started to develop the model that is now called Teachers for Teachers. This model entails a multi-modal approach that combines teacher training, peer coaching and mobile mentoring as strategies to improve the quality of professional development opportunities available and to extend continued support to teachers (see Mendenhall, 2017, for more details about this project). We piloted this new approach from May 2016 through August 2017 with 130 refugee and national teachers working in the Kakuma camp. Teacher training took the form of workshops (utilizing the training pack piloted in Kakuma the previous summer) through which international and local partners led in-person training sessions with cohorts of approximately 25-30 teachers. Training topics included teacher's role and well-being; child protection, well-being and inclusion; pedagogy; and curriculum and planning. Trainings were interactive, practical and drew on local expertise in the Kakuma context.

The teaching corps in Kakuma is predominately male and our first cohort reflected that imbalance with just 17 female teachers to 113 male teachers. Given that many of the female teachers were more reserved than their male counterparts during training sessions, we are creating one all-female cohort this year to explore the extent to which gender configurations may help or hinder the training experience for women. Teachers from South Sudan also made up a significant proportion of the total teaching corps, though we had mixed groups throughout with teachers from other countries, including Burundi, Democratic Republic of Congo, Ethiopia, Rwanda, Somalia, Sudan and Uganda. Although it merits closer examination, we did not observe any outright tensions between different nationalities or between different ethnic groups from the same country during our training activities. Anecdotally, we do see improvements in bringing together the refugee teachers with the Kenyan teachers who also teach in the camp. Kenyan teachers make up around $20 \%$ of the total teaching population in Kakuma. One Kenyan teacher commented:

You see, in the teaching fraternity, we have national staffs and we have incentive staffs - our colleagues who are from the refugee side. And Teachers for Teachers provided a platform whereby me, as a national [teacher], I join my friends who are refugees. That one now made us be like we are one. It provided a platform to make us to be one. And in that I found it now a bit of... a good ground for them to understand me and for me to understand them at that level.

Once teachers completed the initial training workshop, they moved into the coaching phase. Small groups of teachers connected with a peer coach, another teacher from their training cohort, who facilitated continuous opportunities for learning through Teacher Learning Circles and classroom visits. The three-day peer coach training to help prepare teachers for this new role emphasized adult learning, positive leadership, supportive 
communication and goal setting.

Upon completion of the training, all participating teachers were also assigned a global mentor, who provided online practical support for approximately six months. Global mentors were recruited and trained through online webinars to connect with groups of four to five refugee and national teachers over WhatsApp. Global mentors and teachers connected on a regular basis to share experiences, offer teaching tips through a complementary mobile mentoring curriculum, and problem-solve in real-time with teachers on issues they face in the classroom. Safaricom, a Kenyan telecommunications company, generously provided smartphones and credit for airtime, data and text messaging for all participating teachers, which greatly facilitated the mobile mentoring activities. ${ }^{3}$

The integrated and continuous nature of the Teachers for Teachers approach aimed to provide robust professional development support by creating safe spaces for teachers to test new strategies, boost their confidence and overall identity as teachers, grapple with challenges, collaborate with fellow teachers and celebrate their successes. We have continued to conduct complementary and participatory research in alignment with these professional development activities. Our mixed-methods approach has included pre- and post-training questionnaires, classroom observations, Teacher Learning Circle logs, interviews and focus group discussions with teachers, teachers' reflective journals, and a Most Significant Change (MSC) technique that asked teachers to reflect on what had changed the most in their teaching practice during their participation in the program.

Teachers are instrumental to the success of the Teachers for Teachers initiative. Whether they help to adapt training materials, co-facilitate or lead training sessions, support one another as peer coaches, collect monitoring and evaluation data, or share their reflections through focus group discussions and personal stories, teachers are and should be central players in efforts to strengthen the support we offer in crisis-affected and displacement contexts.

\section{What Have We Learned to Date from this Approach?}

Our research-practice activities indicate that our efforts to better support teachers pay dividends in improving their teacher identity and teacher-student relationships. First, working with teachers to help improve their knowledge and skills leads to stronger teacher self-confidence, which in turn leads to a more positive sense of well-being and increased levels of motivation, which

\footnotetext{
${ }^{3}$ It is important to note, however, that in an early prototype of the mobile mentoring approach, teachers were able to participate in these activities with their own phones (e.g., basic, feature or smart), an approach we will return to in the future as we test the long-term sustainability of this model. There is also significant technological development and innovation currently taking place in Kakuma, led by Vodafone and their Instant Network Schools initiative, which means more teachers will have access to the internet at key locations throughout the camp.
} 
ultimately leads to a stronger sense of overall teacher identity. One teacher shares what this feels like:

The strategies have also given me a lot of confidence. I feel very, very confident whenever I go to the class. I have the feeling that I am doing the right thing all the time. It also give[s] me a bit of motivation. Apart from the fact that my learners are enjoying [class], it really motivates me... when I see them smiling, participating, I feel better. I feel totally better. (Male teacher, South Sudan, June 2017)

Second, confident, motivated and emotionally well teachers experience significant improvements in their relationships with their students; in fact, improved teacher-student relationships were the most commonly cited example offered by teachers. A teacher reflects on some of the changes he has experienced as a result of participating in the program:

[T] he strategies that I gained in Teachers for Teachers is helping me a lot. Now [I] build relationships between me and my learners... Before I was having just a small relationship with the learners, not like the way I have gained from Teachers from Teachers. You know in that relationship, maybe I was feeling like them because [I recently] came from high school. I thought I'm just like them. So I act the way...they are acting. If they have high tempers, I have to react like the way they are. But when I learned that I'm a teacher from Teachers for Teachers, then it buil[t] my attitude. [I]t shows that me, I'm someone, I'm someone different from the learners, and I'm the right person to shape them. I'm responsible for them. (Male teacher, South Sudan, July 2017)

Third, while it will eventually be important to be able to measure the impact of this approach on student learning to the extent that we can, we feel strongly that the enhanced focus on teachers at this early juncture is equally critical. Teachers with strong pedagogical practices, confidence, motivation, and well-being will be better placed to then focus on improving their and their students' content knowledge and overall learning outcomes. The emphasis on teachers merits attention, and improvements in teacher practice and on teacher identity are equally important goals in our collective efforts to provide quality education and learning opportunities for all children.

Finally, in addition to the emerging benefits of this approach to the teachers working in the camp, our team members and global mentors are also benefiting greatly from these relationships and learning more about what teaching in crisis-affected contexts entails. As a result of these exchanges, there is potential for teachers working in comparatively stable contexts to improve their teaching practice and perhaps develop deeper empathy and understanding for their learners, particularly in classrooms where teachers are working to accommodate refugee and immigrant children and youth. A recently recruited global mentor interested in volunteering her time to the program stated that "sharing knowledge and supporting teachers in a refugee context cultivates empathy and would be mutually beneficial for our 
respective personal and professional development. I welcome the cultural exchange and learning more about life as a refugee." This type of engagement provides all of us with opportunities to reflect on the teaching profession, to wrestle with the challenges that teachers have to overcome across myriad educational contexts and to potentially build a robust community of practice at a global scale to establish support mechanisms, facilitate knowledge-sharing, and participate in shared advocacy efforts across national contexts.

\section{Social Justice for Teachers}

Teachers are critical to improving our local, national and global communities. As a teacher in Kakuma clearly stated: "You see even me... if it were not for [a] teacher, I would not be here. Even the doctor would not be a doctor if the teacher did not teach, even a pilot comes through the teacher. A teacher, I can say, is everything" (Female teacher, Ethiopia, July 2015). While a teacher "posits possibility, open-ness, and alternative... [and] points to what could be, but is not yet," (Ayers in Guyton, 2008, p. 108), there is no more important place to create this type of environment than in refugee camps and other settings of displacement among teachers, youth and children facing "unknowable futures" (Dryden-Peterson, 2017). One teacher reflected on her role as follows:

Being a teacher to me is very important because teachers empower the community with knowledge [and] skills... That is what I'm doing, I'm empowering the community. As refugees here we want... at [sometime in the future], if they leave with something going to their places. (Female teacher, Uganda, July 2015)

While we might not know what the future entails for the individuals, families and communities affected by crisis, teachers working in these settings who are committed to helping their students become literate, numerate and civically engaged, both need and deserve our help.

While efforts to improve teacher professional development and to establish communities of practice are important, they are only part of the solution. If we want to uphold notions of social justice, we must simultaneously work to effect change in the policy sphere to ensure that teachers working in these contexts have fair policies in place regarding recruitment, training, certification and compensation, in both home and host countries. The various institutional stakeholders responsible for these policies - i.e., national governments and local, national and international organizations working in these spaces - need to work collectively to make significant improvements in both practices and policies for teachers. Those of us interested in partnering in these efforts, including higher education institutions, also need to address in a more concerted way the policy and funding challenges that will ultimately hinder any progress made to improve teachers' knowledge, skills 
and sense of professional identity. We must collectively aspire and take action to match Jackie Kirk's indefatigable efforts to help improve the lives of teachers by authentically engaging with teachers to meet these goals.

\section{References}

Burns, M., \& Lawrie, J. (Eds.). (2015). Where it's needed most: Quality professional development for all teachers. New York: Inter-Agency Network for Education in Emergencies.

Dryden-Peterson, S. (2017). Refugee education: Education for an unknowable future. Curriculum Inquiry, 47(1), 14-24.

Emdin, C. (2016). For white folks who teach in the hood... and the rest of $y^{\prime}$ all too: Reality pedagogy and urban education. Boston, MA: Beacon Press.

Guyton, E. (2008). Social justice in teacher education. The Educational Forum, 64(2), 108-114.

Kirk, J., \& Winthrop, R. (2007). Promoting quality education in refugee contexts: Supporting teacher development in Northern Ethiopia. International Review of Education, 53, 715-723.

Ladson-Billings, G. (1995). Toward a theory of culturally relevant pedagogy. American Educational Research Journal, 32(30), 465-491.

Mendenhall, M. (2017). Strengthening teacher professional development: Local and global communities of practice in Kakuma Refugee Camp, Kenya. London: Save the Children, UNHCR \& Pearson.

Mendenhall, M., Dryden-Peterson, S., Bartlett, L., Ndirangu, C., Imonje, R., Gakunga, D., ... Tangelder, M. (2015). Quality education for refugees in Kenya: Pedagogy in urban Nairobi and Kakuma Refugee Camp settings. Journal on Education in Emergencies, 1(1), 92-130.

Nicolai, S. et al., (2016). Education cannot wait: Proposing a fund for education in emergencies. London: Overseas Development Institute.

UNHCR. (2017). UNHCR Kakuma: Population statistics by country of origin, age, sex and age group. Retrieved from: https://data2.unhcr.org/en/documents/download/57657 